\title{
Merkel Cell Carcinoma on the Right Calf in Association with Chronic Lymphocytic Leukemia, Basal Cell Carcinoma, and Seborrheic Keratosis: a case report
}

Sepideh Babaniamansour ${ }^{1}$, Mohammad Dehghani Firouzabadi², Hamideh

Mohammadzadeh $^{3}$, Mohammadreza Majidi ${ }^{3}$, Abolfazl Zare ${ }^{3}$, and Sepideh KarkonShayan ${ }^{4}$

${ }^{1}$ Islamic Azad University Tehran Medical Sciences

${ }^{2}$ Iran University of Medical Sciences

${ }^{3}$ Gonabad University of Medical Sciences

${ }^{4}$ Affiliation not available

March 13, 2021

\begin{abstract}
Merkel cell carcinoma (MCC) is a rare tumor with neuroendocrine origin. It presents as a single red nodule in the sun-exposed area by rapid and aggressive growth. This study presented a rare case of MCC on an unusual site, associated with chronic lymphocytic leukemia.
\end{abstract}

\section{Hosted file}

Manuscript.pdf available at https://authorea.com/users/401354/articles/513470-merkel-cellcarcinoma-on-the-right-calf-in-association-with-chronic-lymphocytic-leukemia-basal-cellcarcinoma-and-seborrheic-keratosis-a-case-report

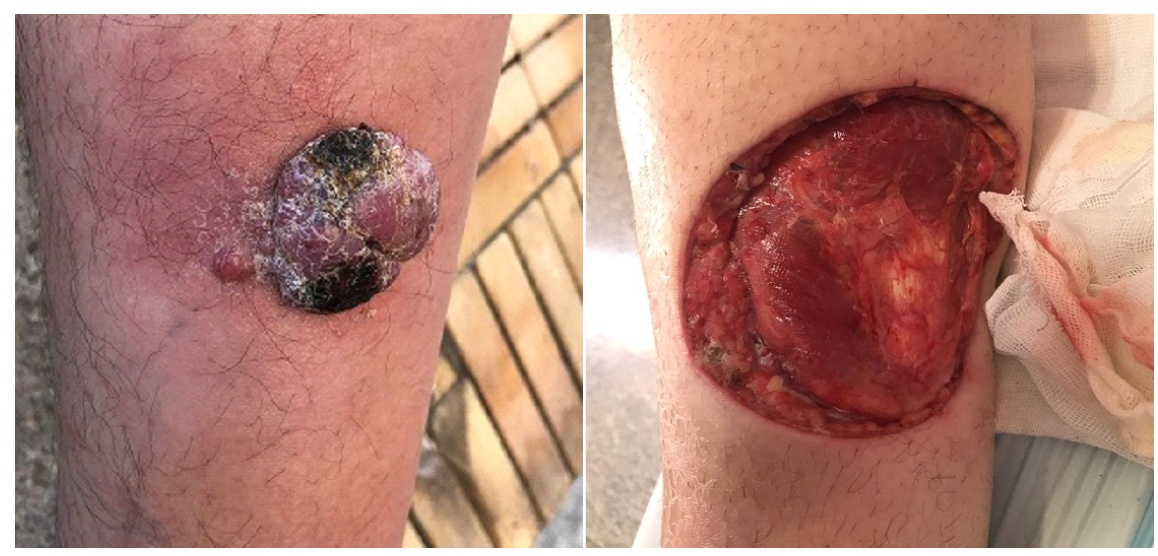




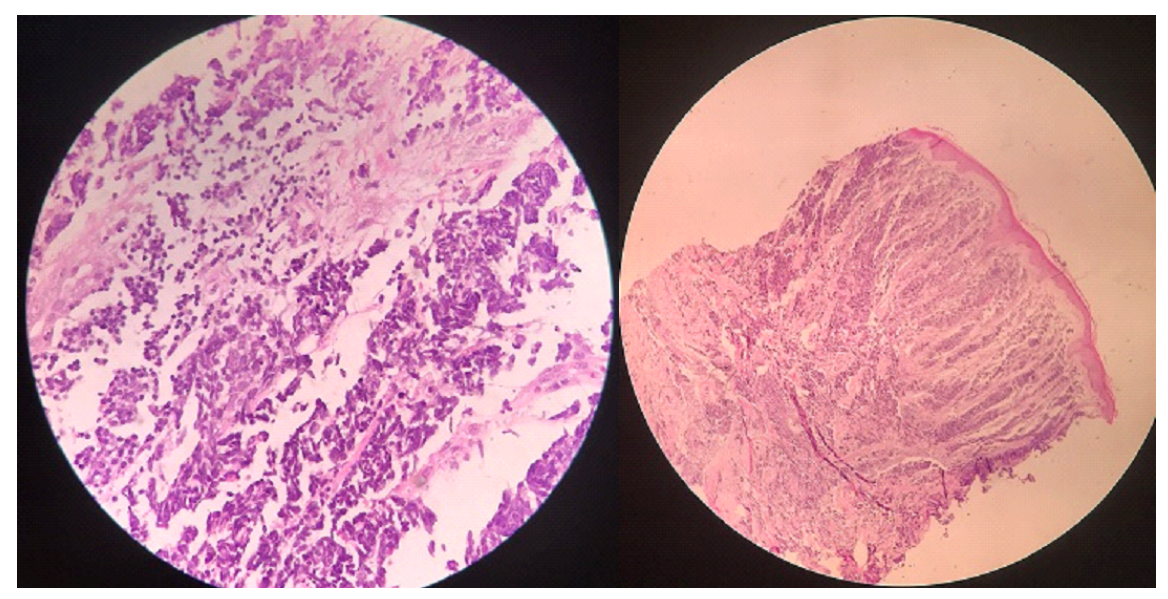

